\title{
The Strategic Importance of Digital Advertising - A Overview
}

\author{
Dr. Shaik Mahammad Shareef* \\ BPR, MA, MCJ, MPhil, PhD, Faculty, Yogi Vemana University, Department of Journalism, Kadapa. Andhra \\ pradesh. \\ *Corresponding Author: Dr. Shaik Mahammad Shareef, BPR, MA, MCJ, MPhil, PhD, Faculty, Yogi \\ Vemana University, Department of Journalism, Kadapa. Andhra pradesh.
}

\begin{abstract}
The core words Strategic, Strategy and Strategist aptly relate to the Second World War and Adolf Hitler who was directly involved. It is on record how Hitler was successful and came out to be a great winner against the Big Powers that were to be like America, Russia, England, and France. The current topic "The Strategic Importance of Digital Adversiting” assumes serious relevance in the present Corporate World.

The strategies of Digital Advertising Calls for a closer examination as to how strategies such as Search Engine Optimization (SEO), Search Engine Marketing (SEM), Content Marketing, Influencer Marketing, EMail, Direct Marketing are commonly associated with the technical innovation and online advertising. As a result the need for Key Performance Indicators (KPI's) has also been created against which the performance of e-commerce business could possibly be measured.
\end{abstract}

Keywords: Strategic, Digital Advertising, Online Marketing, KPI's, Tools, Advertising effectiveness.

\section{INTRODUCTION}

The Phrase, 'Digital Advertising' used in the title of the paper needs a little more examination to justify its aptness.

According to Advanced Oxford English Dictionary, the word "digital" means having to do with information represented as a series of binary digits as in a computer having to do with computer technology. It also means of a clock or watch showing the time by displaying numbers electronically rather than having a clock face. It also means having to do with a finger or fingers. Digital actually means relating to digits or numbers assigned with value of accuracy.

The term "advertising" means describing a product, service or event in publication or on television or radio in order to increase sales. It gives a simple meaning of trying to fill a job vacancy by publishing the details of it. It also suggests making a fact known. It simply means to advertise is to invite persons with certain qualification and experience, if required, or utilizing an opportunity of job or post by joining in an organization that issues the advertisement.

The other key word, "Strategic" employed in the title carries diverse meaning in diverse ways. It means that forming a part of a long term plan to achieve something. It is also used in the sense of relating to the gaining of long term military advantage. It also relates to weapons for use against enemy territory rather than in battle. These two last two meaning are relevant to Hitler's success as a master strategist for achieving success in the Second World War. The Word "strategy" is the root word of the word "strategic". It means a plan designed to achieve a long term aim. It also gives the meaning of the planning and directing of military activity in a war or a battle. The importance and the relevance of the word "strategic" extend itself to the modern business World in as much as the success of any business product depends on it.

Of all the types of advertising, the online advertising is the most important and popular Online Advertising is a type of advertising on internet. It is the chief source of increasing number of websites and companies. Today from minus business enterprise to multinational companies and corporations, everyone compulsorily incorporates online advertising into their marketing strategy. The online advertising primarily involves at least two firms, the advertiser and the publisher. The first one is the agency which purchase or sponsors the advertisement while the second one is the network which distributes the advertisement for display. Consequent upon the association between technical 
innovation and online advertising, many companies specialize both. For instance, majority of search engines combine their search service with an advertising program in order to exploit the benefits of the key word based search technology by including advertisements in search results. At present entering into the world of digital marketing could be overwhelming, tedious as well as confusing. Multiple platforms to advertise their business leads consumers with the greatest dilemma to come to a decision. The cost effectiveness and its results are the two important issues for every customer desirous of going for marketing.

\section{DEVELOPMENT}

There are about Nine (9) Kinds of Advertising Strategies which are enumerated below

1. Web Design

2. E-Mails / Advertising

3. Content / Advertising

4. Social Media / Advertising

5. Influencer/ Advertising

6. Search Engine Optimization

7. Pay-per-click Advertising

8. Geo-fencing Advertising

9. Amazon Advertising.

\section{Web Design:}

It is a form of Website. It is a home online to which innumerable customers approach for information about the products or services offered. It serves itself as the first impression based on which a customer comes to a decision. As the online advertising campaigns are conceived to divert traffic to the website. So websites must be effective enough in order to attract the customers needs. As a result the customers remain longer and continue to stay more invested in what the company offers.

\section{E-Mail Marketing / Advertising}

E-Mail Marketing / Advertising is one of the oldest but still an effective form of digital advertising. The e-mails sent by the company help in reaching the individual clients directly in their inboxes.

\section{Content Advertising}

Various devices like blogs, videos, and info graphics containing information play a key role in content advertising. It indirectly advertises the business to client, sending the updated content helps in creating trust and loyalty towards the branded products in the minds of the targeted audience. Besides, we can also make use of audio-visual elements to attract client's attention.

\section{Social Media Advertising}

The Facebook, Twitter and Instagram are the most important devices that work for social media advertising. These devices offer limitless opportunities to reach and connect potential customers. They become the best platforms in order to advertise online. These social platforms allow the company select their audience based on demographic factors like age, gender and loation and options like interests and behavior.

\section{Influencer Advertising}

Influencer Advertising is yet another effective advertising strategy in which companies of all dimensions starting from big brands to minute startups employs influencer advertising to create brand awareness, build trust and generate sales. Apart from partnering with an influencer, they promote any brand, products, or services on their sustained channels. Influencers are also able to integrate themselves into advertising campaigns. 


\section{Search Engine Optimization}

It immensely helps several potential clients to find the company's website. It also helps the website to rank well in search engines like Google for searches relating to the company's products or services. In SEO, Key words relating to the products or services on a website are incorporated. Consequently the clients type those keywords in search engines like Google, relevant pages appear in results. Some good keywords are chosen through an extensive key word research. These keywords are those which are commonly used by the target audience to attract them to the website. The sites SEO can be improved by publishing original content around the target Keywords and earning links from other dominant sites online. The right strategy, if employed, will improve the site's rankings, gain more traffic and generate more leads and conversion.

\section{Pay-per Click Advertising}

PPC which means Pay-per-click advertising isi an online advertising model that allows customer to place advertisements in search engine results for specifi keywords. PPC allows a customer to pay for placements for their target Keywords. PPC works based a bidding system in which a customer selects the target key words. Its highest bid will earn the placement above organic search results, if anyone clicks, the company will pay the bid amount. The main characteristic of PPC is that the payment will be made only when customers click on the company's advertisement. It means that the company's budget is not wasted on those who are not interested in the business or ignore the advertisements.

\section{Geo fencing Advertising}

Geo fencing Advertising is one of the best online advertising strategies by which a business creates a virtual fence around a specific area like a software company competitor location or conference center. When a customer enters this fence it will be added to remarketing audience. The company can then re market to these clients. It can help to build their brand awareness, guide their next shopping trip or influence their company's requests or proposals from next quarter. This unique internet advertising agency strategy offers a business a new innovative and effective way to reach the target audience.

\section{Amazon Advertising}

Next to Google and Facebook, Amazon Advertising is one of the best ways of advertising strategy to advertise online. Through Amazon Advertising strategy, the business can promote their products and brand in Amazon research results, product pages. A company can advertise on not only Amazon but also Amazon owned sites like IMDB in order to build brand awareness.

Providing a comprehensive advertising strategy is very much essential. Since more than 50 percent of product searches on Amazon against Google, it is worth considering the positive impact of this internet advertising strategy.

\subsection{Analysis and Discussion}

Some Key factors are listed below that we should consider while measuring the performance of the Digital Advertising initiatives.

The metrics are required to be identified against which the success will be measured. Some of the most important metrics are mentioned here under

\section{a) Traffic:}

Changes in the volume or type of traffic to the website are a good sign of whether the digital advertising strategies are effective or not. This includes factors such as overall site traffic where the clients come from.

\section{b) Click through Rate (CTR)}

The paid advertisements or e-mail advertising is an essential part of advertising campaign. Then a click through rate can indicate which content is gaining the most clicks from the customers.

\section{c) Cost Per Click}

While running advertisement campaigns, we should look at how much a visitor is paying per click on his advertisement. 


\section{d) Conversions}

In an e-commerce business conversions may be defined as product sales on the company's website. The sales can be measured against those of previous periods to see how the digital advertising efforts can improve business.

\section{How To Measure Digital Advertising Success}

Google appointed a study group from E-Consultancy in 2016 and it is revealed that the top performing brands exceeded their performance against their estimated goals.

Measuring advertising strategies requires a closer look at diverse phases which are mentioned here under

\section{a) Awareness Phase:}

In this phase creating awareness through announcements, a new phone, new fashion collection, a new way to navigate an online shopping site will play an important role. Measuring success of efforts made at the awareness phase is all about unique reach brand awareness advertisement recall.

\section{b) Consideration Phase:}

In this phase customers search more specifically for something that they want to consider the company's product. One of the ways to measure this via paid search is that higher click through rates is an indication of higher engagement with the advertisement from a website perspective; this can be measured through time on site and number of page views per session.

\section{c) Purchase Phase:}

In every phase diverse factors workout for potential measurement. In the purchase phase when the customer is ready to press the buy button, conversion phase will set in to account for the correct measurement. Through this measurement tool, detailed data is to be explored. These details include.

a) Audience:

It indicates where a customer comes from, whether or not he/she is new or a returning client, kind of device used mobile versus desktop versus tablet and all other additional demographics. When we understand more about who is coming to the site, he/she can cater to their needs.

\section{b) Acquisition:}

We understand the people who are visiting the company's website, which traffic source they are coming from-paid Google Channels, Organic ones or social media or any other referral source in order to judge its real worth and value.

\section{c) Behavior:}

We can understand the behavior of the customers and find out what they are doing. Thereby there is less focus on who they are and how they come to the company's website but rather on an understanding the customer's journey flow. This is the content driven part on the site. Then we can judge whether some are more popular than others. The most important part is measuring the customer's journey.

\section{d) Conversion:}

Through an enhanced E-Commerce we can measure conversion of the consumer. This will help in measuring the customers who add products to an online shopping cart who go through the checkout funnel in order to find out who abandon and those who finally decide to purchase. It is a more powerful device to familiarize with the customers.

\section{CONCLuSion}

During the Second World War the success of Adolf Hitler mainly lay in the secret of administering a powerful injection to his soldiers where by while fighting against the enemy even if they were wounded, they could fight valiantly killing their enemy. Thus the German soldiers could withstand their pain. Similarly the strategies importance of Digital Advertising also stretches itself to achieve marvelous success in this Corporate World by adopting them systematically. Now a days it is not 
sufficient to estimate what works and what does not in individual advertising campaigns. Diverse devices exist to estimate and measure results through websites when properly employed. The data they produce should be effectively used in order to determine the effectiveness of any advertising campaign adopted by the company. For many years the corporate companies struggled. It is pertinent that a company employs the analytical advertising tools that are available to collect data today and it to develop the future advertising campaigns that would ensure success of any business in this highly Competitive World.

\section{REFERENCES}

[1] Calcott L., Weller B. (2012), The Definitive Guide to Google AdWords: Create Versatile and Powerful Marketing and Advertising Campaigns. New York: Apress, p.9 Google Scholar.

[2] Chaffey, D. and Ellis-Chadwick, F. (2012). Digital Marketing: Strategy, Implementation and Practice. $1^{\text {st }}$ ed. Harlow: Pearson Education.

[3] Dodson, I. (2016). The art of digital marketing: the definitive guide to creating strategic, targeted and measurable online campaigns. Hoboken, New Jersey: Wiley. ISBN 9781119265702.

[4] Guziur P. (2011), Internet marketing - small and large business strategies. Glilwice: Helion, p.92. Google Scholar.

[5] Kryriski M. (2014), Evaluation of the effectiveness online advertising. Elaboration unpublished: Lublin .Goolge Scholar.

[6] Nielsen (20 January 2016). "Connected Commerce is Creating Buyers Without Borders". Nielsen Global. Nielsen Global. Retrieved 24 March 2016.

[7] Pratik Dholakiya (14 April 2015). "3 Digital Marketing Channels That Work for Every Advertiser". Enterpreneur. Retrieved 17 October 2015.

[8] Square2Marketing (2012). "Online advertising: Google Adwords \& pay-per-click". YouTube. Retrieved 10 January 2018.

Citation: Dr. Shaik Mahammad Shareef. "The Strategic Importance of Digital Advertising - A Overview". International Journal of Media, Journalism and Mass Communications (IJMJMC), vol 7, no. 1, 2021, pp. 0913 doi: http://dx.doi.org/10.20431/2454-9479.0701003.

Copyright: () 2021 Authors. This is an open-access article distributed under the terms of the Creative Commons Attribution License, which permits unrestricted use, distribution, and reproduction in any medium, provided the original author and source are credited. 